\title{
Use of specific combinations of the triphala plant component extracts to potentiate the inhibition of gastrointestinal bacterial growth
}

Gagan Tiwana, ${ }^{\mathrm{a}, \mathrm{b}}$ Ian E. Cock, ${ }^{\mathrm{c}, \mathrm{d}^{*}}$ Alan White ${ }^{\mathrm{c}}$, Matthew J. Cheesman, ${ }^{\mathrm{a}, \mathrm{b}^{*}}$

a School of Pharmacy and Pharmacology, Gold Coast Campus, Griffith University, Parklands Drive, Southport, Queensland 4222, Australia

${ }^{\mathrm{b}}$ Menzies Health Institute Queensland, Quality Use of Medicines Network, Queensland 4222, Australia

${ }^{c}$ School of Environment and Science, Nathan Campus, Griffith University, 170 Kessels Rd, Nathan, Queensland 4111, Australia

${ }^{\mathrm{d}}$ Environmental Futures Research Institute, Nathan Campus, Griffith University, 170 Kessels Rd, Nathan, Queensland 4111, Australia

*Authors of correspondence: ～Dr. M.J. Cheesman: m.cheesman@griffith.edu.au

Dr. I. E. Cock: E-mail: I.Cock@griffith.edu.au 


\begin{abstract}
Ethnopharmacological relevance: Triphala is used in Ayurveda to treat a wide variety of diseases, including numerous bacterial infections. Interestingly, the plant components of triphala (Terminalia bellirica, Terminalia chebula and Emblica officinalis) are also good inhibitors of bacterial growth when used individually, yet plant preparations are generally used in combination in traditional medicine. Surprisingly, no previous studies have addressed the reason why the combination is preferred over the individual components to treat bacterial infections.
\end{abstract}

Aim of the study: To test and compare the antibacterial efficacy of triphala and its component parts to quantify their relative efficacies. The individual plant components will also be tested as combinations, thereby determining whether combining the individual components potentiates the antibacterial activity of the components used alone.

Materials and methods: Triphala and the three individual plant components were extracted using solvents of varying polarity (methanol, water, ethyl acetate) and the antibacterial activity of the aqueous resuspensions was quantified by disc diffusion and broth microdilution MIC assays. Combinations of extracts produced from the individual components were also tested against each bacterial species and the $\Sigma$ FICs was calculated to determine the class of interaction. Where synergy was detected, isobologram analysis was used to determine the optimal component ratios. The Artemia nauplii bioassay was used to test for toxicity and GC-MS headspace profiling analysis was used to highlight terpenoid components that may contribute to the antibacterial activity of triphala.

Results: The aqueous and methanolic triphala, T. bellirica, T. chebula and E. officinalis extracts displayed good inhibitory activity against all bacterial strains, with MICs often in the 250-750 $\mu \mathrm{g} / \mathrm{mL}$ range. The methanolic extracts were generally more potent than the aqueous extracts and $T$. chebula was the most potent of the individual plant components. Combining the extracts of the different plant species resulted in potentiation of the growth inhibitory activity of most combinations compared to that of the individual components. Indeed, with the exception of $S$. flexneri, all bacterial species were potentiated by at least one combination of methanolic plant extracts, with a substantial proportion of these displaying synergistic interactions. All extracts were found to be either non-toxic, or of low to moderate toxicity in Artemia nauplii assays.

Conclusion: Whilst the individual plant components of triphala all inhibit the growth of multiple pathogenic bacteria, the activity is potentiated for multiple combinations. Therefore, 
the traditional usage of the combination of the three plant materials in triphala not only extends the activity profile of the mixture over that of the individual components, but it also substantially potentiates the inhibitory activity towards multiple bacteria, partially explaining the preference of triphala compared to the individual components.

Keywords: Ayurveda, Triphala, antibacterial, synergy, GC-MS analysis

\section{Introduction}

Triphala (TA) is a popular polyherbal Ayurvedic medicine which has been used for more than 1000 years (Mukherjee et al., 2017). It comprises three separate dried fruit powders mixed in equal proportion: Terminalia bellirica (Gaertn.) Roxb. (TB), Terminalia chebula Retz. (TC) and Emblica officinalis L. (EO), all of which are native to the Indian subcontinent. The formula possesses significant ethnopharmacological importance due to its broad array of therapeutic applications that include treatments for obesity, diabetes, cardiovascular conditions, cancer, cataracts, inflammation and ageing, as well as many diseases triggered by microorganisms (Baliga et al., 2012).

Triphala is a treatment option for various ailments associated with the gastrointestinal system. Interestingly, it has been found to possess both anti-diarrhoeal (Biradar et al., 2008) and laxative (Mukherjee et al., 2006) properties. The mechanisms via which these conditions are ameliorated remains unclear, although it is possible in cases of diarrhoea caused by enteric infections that antimicrobial properties inherent in the triphala formulation are responsible. Diarrheagenic Escherichia coli (Cabrera-Sosa \& Ochoa, 2020) is a common trigger of diarrhoea especially in children, while Staphylococcus aureus has been identified as a causative agent involved in antibiotic-associated nosocomial diarrhoea (Polage et al., 2012). Bacillus cereus releases diarrheagenic toxins in food poisoning cases (Bhunia, 2018). Shigellosis is triggered by Shigella spp. including Shigella flexneri and Shigella sonnei (Kotloff et al., 2018). A recent outbreak of fatal diarrhoea was attributed to Aeromonas hydrophila (Liu et al., 2019), whilst other food-borne strains such as Salmonella Typhimurium (Wotzka et al., 2017) inhabit the lower gut and cause acute diarrhoea.

There have been reports of antimicrobial activity of triphala towards these strains, although the activity determinations vary widely among the individual studies. As an example, a 2007 study showed that the aqueous extract of E. officinalis was inactive against $S$. aureus on agar disc diffusion assays but possessed a low minimum inhibitory concentration (MIC) of $100 \mu \mathrm{g} / \mathrm{mL}$ in broth assays (Srikumar et al., 2007). In contrast, a later study reported a 
substantially lower MIC value $(25 \mu \mathrm{g} / \mathrm{mL})$ for these extracts against the same strain (Mehrotra et al., 2010). Other studies have shown antibacterial activity of triphala (and its separate plant components) against E. coli, S. aureus, and S. Typhimurium in disc diffusion experiments, although these studies employed very large concentrations or quantities of the extracts (3-10 mg per disc) in the assays (Amanullah et al., 2010; Tambekar and Dahikar, 2011; Sheta et al., 2016). Furthermore, these studies tested a limited number of extract doses and MIC values were not determined, making comparisons between studies impossible. In some cases, gram quantities of extract were used in assays (Mahajan and Jain, 2015) or the amount of extracts used was not stated (Parveen et al., 2018). Maji et al. (2010) documented the activity of $E$. officinalis aqueous extracts against $B$. cereus, although the other plant components and the triphala formulation were not tested. Activities against $S$. Typhimurium have been reported although the results are dubious as the extracts were resuspended in 100\% DMSO for testing (Tambekar et al., 2007). Dimethyl sulfoxide itself is toxic to bacteria and it is likely that this accounts for the growth inhibitory activity reported in that study. Another study showed low MIC values for aqueous extracts of triphala and each of its three components in a broth microdilution assay against $S$. flexneri and $S$. sonnei, although zones of inhibition were not observed for T. bellirica, E. officinalis and the Triphala formulation using agar disc diffusion assays (Srikumar et al., 2007; Amanullah et al., 2010). These inconsistencies between the activities of triphala and its components, and/or the techniques used to determine the activities, warrant further investigation. Additionally, we were unable to find reports of the effects of triphala against $A$. hydrophila in the literature.

Despite the traditional use of triphala as a 1:1:1 formulation of the three plant components, little is known about the effectiveness of these plants as antibacterial agents when T. bellirica, T. chebula and E. officinalis are used in different combinations and proportions. It may be possible that different mixtures of the individual components address different aspects of the disease progression or deliver an expanded antibacterial spectrum. Alternatively, in some cases, the combinations may synergise antibacterial activities against specific microorganisms (van Vuuren \& Viljoen, 2011). This has been demonstrated in the past where combinations of extracts or essential oils prepared from different plants synergistically inhibit bacterial or fungal growth (Sibanze et al., 2010; de Rapper et al., 2013; Mabona et al., 2013; Orchard et al., 2018a; Orchard et al 2018b; Orchard et al, 2019). While triphala and its individual components possess antibacterial activities against a number of pathogens, as previously stated, the benefits 
of combining the individual components rather than using them in isolation are hitherto unknown.

In the present study, we aim to verify the activities of these plants against a panel of seven bacterial pathogens known to trigger and/or exacerbate gastrointestinal diseases, and to determine whether combinations of T. bellirica, T. chebula or E. officinalis alter the spectrum and efficacy of the therapy. E. faecalis was also included in the study as a non-pathogenic species present within the human alimentary tract (Murray, 1990) in order to compare the effects of the extracts on this strain with those on pathogenic bacteria. Furthermore, we also sought to detect additive or synergistic interactions and determine the nature of those interactions. Thereby, we aimed to elucidate options to optimise therapeutic formulations to treat enteric infections that trigger diarrhoea. This would be particularly useful where activities can be significantly enhanced using specific combinations of the components. Therefore, this study aimed to provide an ethnomedicinal basis for adjusting formulations targeted against specific illnesses that are triggered by pathogenic gastrointestinal strains.

\section{Materials and Methods}

\subsection{Source of plant samples}

Triphala, T. bellirica, T. chebula and E. officianalis plant materials were sourced commercially from Noodles Emporium, Australia and supplied as dried and ground powdered forms. All plants were sourced from India and were verified by the supplier. Voucher samples have also been stored at the School of Environment and Science, Griffith University (Nathan, QLD). Voucher numbers are GU-TA19, GU-TB19, GU-TC19 and GU-EO19 for triphala, $T$. bellirica, T. chebula and E. officianalis, respectively.

\subsection{Preparation of extracts}

A $1 \mathrm{~g}$ mass of triphala, T. bellirica, T. chebula and E. officinalis powders were weighed into individual tubes and either deionised water, methanol or ethyl acetate added to a volume of $50 \mathrm{~mL}$. All solvents were supplied by Ajax Fine Chemicals, Australia and were AR grade. This ultimately produced 12 different extracts (four botanical samples extracted with three different solvents). The samples were mixed by continuous rolling at $30 \mathrm{rpm}$ for $24 \mathrm{~h}$ at room temperature. Samples were then filtered through Whatman No. 54 filter paper under vacuum into fresh, pre-weighed $50 \mathrm{~mL}$ tubes. Aqueous samples were frozen at $-80{ }^{\circ} \mathrm{C}$ for $30 \mathrm{~min}$ and dried by lyophilisation for $48 \mathrm{~h}$. Organic solvents (methanol and ethyl acetate) were evaporated in a drying oven at $50{ }^{\circ} \mathrm{C}$ for up to $48 \mathrm{~h}$. Dried extracts were weighed and resuspended in 10 
$\mathrm{mL} 1 \%$ DMSO and sonicated three times (20 s pulses at $1 \mathrm{kHz}$ with $30 \mathrm{~s}$ rest between pulses). Samples were sterilised by passage through $0.22 \mu \mathrm{m}$ filters (Sarstedt) and stored at room temperature until use.

\subsection{Qualitative phytochemical analysis}

Phytochemical analyses of the triphala, T. bellirica, T. chebula and E. officinalis extracts were conducted in order to test for the presence of saponins, phenolic compounds, flavonoids, phytosterols, triterpenoids, cardiac glycosides, anthraquinones, tannins and alkaloids using previously described assays (Vesoul and Cock, 2011).

\subsection{Antibiotics and bacterial strains}

Penicillin-G (potency of $1440-1680 \mu \mathrm{g} / \mathrm{mg}$ ), chloramphenicol ( $\geq 98 \%$ purity by HPLC), erythromycin (potency $\geq 850 \mu \mathrm{g} / \mathrm{mg}$ ), ciprofloxacin ( $\geq 98 \%$ purity by HPLC) and tetracycline ( $\geq 95 \%$ purity by HPLC) were purchased from Sigma-Aldrich (Australia) and were used as controls for the disc diffusion and microplate broth microdilution assays. Reference bacterial strains of Escherichia coli (ATCC 25922), Enterococcus faecalis (ATCC 19433), Shigella sonnei (ATCC 25931), Aeromonas hydrophila (ATCC 7966), Salmonella Typhimurium (Salmonella enterica serovar Typhimurium; ATCC 14028), Shigella flexneri (ATCC 12022), Staphylococcus aureus (ATCC 25923) and Bacillus cereus (ATCC 14579) were purchased from the American Type Culture Collection (ATCC; USA). All strains were sub-cultured and maintained in nutrient broth and on nutrient agar (Oxoid Ltd., Australia), and the antibacterial test conditions conformed to CLSI standardised methods (Clinical and Laboratory Standards Institute, 2019).

\subsection{Disc diffusion assays}

A modified Kirby-Bauer disc diffusion method was used to determine the antibacterial activity of all plant extracts on agar (Cock, 2008). Individual bacterial colonies for each strain were inoculated into $40 \mathrm{~mL}$ of fresh nutrient broth and incubated at $37{ }^{\circ} \mathrm{C}$ with orbital oscillation at $150 \mathrm{rpm}$ until the cell count reached approximately $10^{8}$ cells $/ \mathrm{mL}$. The cultures were then used to prepare $0.5 \mathrm{McF}$ arland standards for each strain and $100 \mu \mathrm{L}$ of the cultures spread on nutrient agar. Ten microlitres of resuspended extracts (tested undiluted at the concentrations provided in Table 1), the resuspension solvent (1\% DMSO), or the reference antibiotics were infused into filter discs (Whatman \#1 paper, $6 \mathrm{~mm}$ in diameter), allowed to dry and then attached to the agar surface. All samples were tested using triplicate assays. The 
discs were allowed to dry on the plate for $30 \mathrm{~min}$ and the plates incubated at $37^{\circ} \mathrm{C}$ for $18-24$ h. Diameters of the zone of inhibition (ZOI) were measured to the nearest whole millimetre and values included the $6 \mathrm{~mm}$ diameter of the filter discs. Mean values ( \pm SEM) are reported in this study.

\subsection{Determination of minimum inhibitory concentration (MIC) values}

The MICs for each extract and antibiotic was determined using a 96-well micro-titre plate broth microdilution assay (Hübsch et al, 2014; Ilanko and Cock, 2019). Briefly, samples were serially diluted followed by addition of $100 \mu \mathrm{L}$ of a 1:100 dilution of a 0.5 McFarland cell suspension, and the plates incubated at $37{ }^{\circ} \mathrm{C}$ for $20-24 \mathrm{~h}$. Aliquots $(40 \mu \mathrm{L})$ of $p$ iodonitrotetrazolium violet (INTZ; Sigma Aldrich, Australia) dye solution $(0.4 \mathrm{mg} / \mathrm{mL})$ were added into each micro-titre plate well and incubated for $6 \mathrm{~h}$ at room temperature. MIC values were determined by visual inspection as the lowest concentration of extract or antibiotic that completely inhibited bacterial growth as defined as the lack of red-pink colour development. Extract MIC values $>5000 \mu \mathrm{g} / \mathrm{mL}$ were considered inactive; MIC values between $2000-5000$ $\mu \mathrm{g} / \mathrm{mL}$ were considered as low activity; $1000-2000 \mu \mathrm{g} / \mathrm{mL}$ were considered as moderate activity; $400-1000 \mu \mathrm{g} / \mathrm{mL}$ were considered as noteworthy activity; $100-400 \mu \mathrm{g} / \mathrm{mL}$ were considered as good activity; and $<100 \mu \mathrm{g} / \mathrm{mL}$ were considered to be high activity.

\subsection{Fractional inhibitory concentration (FIC) and SFIC determinations}

Extracts showing appreciable antibacterial activity $(<2000 \mu \mathrm{g} / \mathrm{mL})$ were tested in combination with each other, to test whether interactions occurred between the different plant component extracts. Initially, 50:50 ratios of two different extracts were tested. Interactions between extracts were examined by determination of the sum of fractional inhibitory concentrations ( $\Sigma$ FIC) for each combination. The FIC values for each component (a and $b$ ) were calculated using the following equations where $\mathrm{a}$ and $\mathrm{b}$ represent the two plant extracts being tested:

$$
\begin{aligned}
& \text { FIC }(a)=\text { MIC ( } a \text { in combination with } b) / \text { MIC (a independently) } \\
& \text { FIC }(b)=\text { MIC ( } b \text { in combination with a) / MIC ( } b \text { independently) }
\end{aligned}
$$

$\sum \mathrm{FIC}$ was then calculated using the formula $\sum \mathrm{FIC}=\mathrm{FIC}(\mathrm{a})+\mathrm{FIC}(\mathrm{b})$. The interactions were classified as synergistic $\left(\sum \mathrm{FIC} \leq 0.5\right)$, additive $\left(\sum \mathrm{FIC}>0.5-\leq 1.0\right)$, indifferent $\left(\sum \mathrm{FIC}>1.0-\leq 4.0\right)$ or antagonistic ( $\sum$ FIC $\left.>4.0\right)$ (Doern, 2014). 
In instances where the 50:50 ratios of two of the combined components produced synergistic interactions, the combinations were examined further by testing nine different ratios ranging from 10:90 (a:b) to 90:10 (a:b). All combinations were tested in duplicate in two independent experiments $(\mathrm{n}=4)$. Data points for each ratio examined were plotted on isobologram graphs, and these were used to determine the optimal combination ratios that elicited synergy. Data points on or below the 0.5:0.5 line indicated synergy; those above the 0.5:0.5 line, and up to and including the 1.0:1.0 line, indicated an additive interaction; data points above the 1.0:1.0 line indicated indifferent interactions.

\subsection{Artemia nauplii lethality screening}

The toxicity of the extracts and controls was quantified using standard Artemia franciscana Kellogg nauplii lethality assays (ALA) (Ruebhart et al., 2009). Briefly, $400 \mu \mathrm{L}$ volumes of the diluted plant extracts or the controls were added $400 \mu \mathrm{L}$ of artificial seawater containing 40-60 newly hatched $A$. franciscana nauplii (within 1 day of hatching) in individual wells of a 48 well plate. Negative controls (32 g/L artificial seawater; Sigma Australia) and positive controls $\left(1 \mathrm{mg} / \mathrm{mL}\right.$ potassium dichromate $\left(\mathrm{K}_{2} \mathrm{Cr}_{2} \mathrm{O}_{7}\right)$ (AR grade, Chem-Supply, Australia) were included on all plates. After a $24 \mathrm{~h}$ incubation at $25 \pm 1{ }^{\circ} \mathrm{C}$, the percentage of dead nauplii was determined. The $\mathrm{LC}_{50}$ values were calculated as the concentration of extract or control required to kill $50 \%$ of the A. franciscana nauplii, and were determined using Probit analysis. The results are expressed as the mean of three independent experiments, each with internal triplicates $(n=9)$. To determine the suitability of the extracts as potential therapeutic agents, their therapeutic index was calculated using the formula:

Therapeutic index $(\mathrm{TI})=\left(\mathrm{LC}_{50}\right) /(\mathrm{MIC})$

\subsection{GC-MS profiling analysis}

Separation, identification and quantification of the relative abundance of individual extract components putative was performed using a Shimadzu GC-2010 plus (USA) chromatography system linked to a Shimadzu MS TQ8040 (USA) mass selective detector system using previously optimised parameters (Shalom \& Cock, 2018). The mass spectrometer was operated in the electron ionisation mode at $70 \mathrm{eV}$ and the individual mass signals were recorded in total ion count (TIC) mode. The TIC was acquired for 45 mins utilising a mass range of $45-450 \mathrm{~m} / \mathrm{z}$. Individual compounds were putatively identified by comparison with the ChemSpider database.

\subsection{Statistical analysis}


ZOI data were expressed as the mean \pm SEM of at least three independent experiments. One-way ANOVA analysis was used to calculate statistical significance between control and treatment groups. Although statistical analysis could not be performed with the 96-well microtitre broth microdilution assays, the reliability of MIC values was ensured by repeating the broth microdilution assays twice on separate days, with two replicates per assay, to confirm that the results were reproducible for all extracts, antibiotics and combinations tested.

\section{Results}

\subsection{Liquid extraction yields and phytochemical screening}

The extraction of $1 \mathrm{~g}$ quantities of dried triphala and its botanical ingredients produced varying yields, ranging from $2-5 \%$ (ethyl acetate) to $40-70 \%$ (water or methanol). All extracts were resuspended in 1\% DMSO to produce the final extract concentrations shown in Table 1. All extracts were found to be rich in flavonoids, tannins and phenolic compounds. However, the methanolic extracts possessed a wider profile of phytochemicals, which included triterpenoids and cardiac glycosides in low to moderate abundances, respectively (Table 1). Alkaloids were present in the aqueous E. officinalis and methanolic T. chebula extracts only. All extracts were devoid of phytosterols and anthraquinones. Saponins were present in high levels in methanolic $T$. chebula extracts and in low levels in aqueous $T$. chebula samples but were absent in all other extracts. Alkaloids were detected in low levels in aqueous E. officinalis and methanolic T. chebula extracts.

\subsection{Antimicrobial activity}

Volumes of $10 \mu 1$ were used directly in the agar disc diffusion assay to produce the activities shown in Fig. 1. The aqueous and methanolic triphala, T. bellirica, T. chebula and E. officinalis extracts exhibited inhibitory activity against most of the bacterial species tested, with some ethyl acetate extracts also inhibiting the growth of some bacteria. It is likely that the much lower yields obtained from the ethyl acetate extractions contributed to their smaller ZOIs on agar plates for samples showing any activity. Furthermore, the levels of inhibition observed on disc diffusion assays were generally concordant with inhibition in broth microdilution assays for both extracts and positive control antibiotics (Fig. 1 and Table 2), in that higher ZOI values (on disc diffusion assays) for any given extract against a bacterial strain produced lower MIC values. No activity was observed against the non-pathogenic species, E. faecalis on agar plates with low activities detected in broth microdilution assays. However, inhibition of the growth of this strain was observed for some of the positive control antibiotics, indicating that the assays 
were functioning correctly. As such, the plant extracts were not tested further against $E$. faecalis.

The methanolic extracts exerted consistently greater efficacies against the pathogenic strains on both agar and in liquid assays. The water and ethyl acetate extracts usually showed either lower levels of activity or fewer of the components were active, although there are instances of high activities for extracts prepared with these solvents (Fig. 1 and Table 2). Interestingly, some of the ethyl acetate extracts that failed to inhibit the growth of some of the strains on agar also produced low MIC values (e.g. S. flexneri and B. cereus, Fig. 1F and 1G and Table 2).

Among the different plant species, the effects of $T$. chebula extracts on bacterial growth on agar was generally stronger against the pathogenic strains than the other plant extracts, with the exception of E. coli, where T. bellirica was more active than T. chebula. It should be noted that in most cases, the methanolic extracts possessed similar activities between the plants, particularly in agar disc diffusion experiments (Fig. 1). Similar trends were noted in broth microdilution assays (Table 2). T. bellirica and T. chebula proved to generally have the best activity for species such as B. cereus, A. hydrophila, S. flexneri, and S. aureus. Low MIC values were also obtained for some of the ethyl acetate extracts against these bacterial strains may have been revealed due to the greater sensitivity of this method.

\subsection{Extract combinations}

Since the methanolic extracts were generally more active, all were tested in combination in two-component systems. The remaining extracts were tested only if both extracts used in combination possessed an MIC value less than $2000 \mu \mathrm{g} / \mathrm{ml}$. These selections were made in order to focus the study on higher potency extracts.

Although E. coli and $S$. sonnei were less susceptible to growth inhibition by the methanolic extracts, combinations of some of the extracts in 50:50 ratios boosted activities (Table 3). Combinations of $T$. bellirica and T. chebula led to synergistic inhibition of growth of E. coli and A. hydrophila, while additive effects were found against S. sonnei and B. cereus. The same effects were found when combinations of T. bellirica and E. officinalis were tested, whilst an additive effect on $S$. aureus was found using this mixture. When $T$. chebula and $E$. officinalis were combined, synergistic inhibition of $A$. hydrophila was produced, while additive effects were observed against E. coli, S. sonnei, S. Typhimurium and B. cereus. 
There were only a limited number of cases where either water or ethyl acetate extracts were sufficiently active for testing combinations. There was a single case for the aqueous extracts, where $T$. bellirica and T. chebula combinations produced synergistic activity on $S$. flexneri $\left(\mathrm{FIC}_{\mathrm{TB}}=0.250, \mathrm{FIC}_{\mathrm{TC}}=0.250, \sum \mathrm{FIC}=0.500\right)$. There were three cases for the ethyl acetate extracts, again involving $T$. bellirica and $T$. chebula, although no interactions were observed against the relevant strains $\left(\mathrm{FIC}_{\mathrm{TB}}=0.501, \mathrm{FIC}_{\mathrm{TC}}=2.179, \sum \mathrm{FIC}=2.680\right.$ for $S$. flexneri; $\mathrm{FIC}_{\mathrm{TB}}=0.500, \mathrm{FIC}_{\mathrm{TC}}=0.500, \sum \mathrm{FIC}=1.000$ for $S$. aureus; and $\mathrm{FIC}_{\mathrm{TB}}=0.500, \mathrm{FIC}$ тС $=1.198, \sum \mathrm{FIC}=1.698$ for $B$. cereus).

The synergistic combinations were particularly interesting because they not only show enhanced efficacy but a vastly greater efficacy than either component alone. Therefore, isobologram analysis was conducted in order to determine which ratio(s) produced synergistic (or additive) effects. These graphs are shown in Fig. 2. Mixtures of T. bellirica and T. chebula, or T. bellirica and E. officianalis, methanolic extracts showed additive inhibition of the growth of E. coli up until 50:50 ratios. However, ratios containing a larger proportion of the second extract produced synergy (Fig. 2A and 2B). The same was observed for T. bellirica and $T$. chebula mixtures against $A$. hydrophila (Fig. 2C). Almost all combination ratios of T. bellirica and $E$. officianalis elicited synergistic inhibition of $A$. hydrophila growth (Fig. 2D). In contrast to Fig. 2A and Fig. 2B, mixtures of T. chebula and E. officinalis methanolic extracts against $A$. hydrophila (Fig. 2E), or T. bellirica and T. chebula aqueous extracts against S. flexneri (Fig. 2F) require a lesser proportion of the second extract, and thus more of the first extract, in order to achieve synergistic inhibition of bacterial growth.

\subsection{Artemia lethality assay (ALA)}

All extracts were tested in the Artemia nauplii bioassay across a range of concentrations and were deemed to be toxic if they possessed $\mathrm{LC}_{50}$ values $<1000 \mu \mathrm{g} / \mathrm{mL}$ following $24 \mathrm{~h}$ exposure (Ruebhart et al., 2009). LC50 values could not be calculated for the methanolic $T$. bellirica and T. chebula extracts or the ethyl acetate triphala and T. bellirica extracts, as nauplii death did not occur at any concentration screened. However, an LC50 value of $750 \mu \mathrm{g} / \mathrm{mL}$ was found for all aqueous extracts, the methanolic triphala and E. officianalis extracts, and the ethyl acetate $T$. chebula and E. officianalis extracts, indicating a mild level of toxicity of these preparations under these assay conditions.

\subsubsection{Therapeutic index (TI) of the extracts}


To evaluate the suitability of the tested extracts as therapeutic agents, the therapeutic index (TI) was calculated for all extracts against each bacterial pathogen. We were unable to calculate TI values for the methanolic T. bellirica and T. chebula extracts or the ethyl acetate triphala and $T$. bellirica extracts, as they did not display toxicity at any concentration tested and are indicated as by the term "High" in Table 4. Due to their lack of toxicity, these were assumed to have high TI values. The TIs of these extracts are therefore noteworthy and indicate that these extracts are suitable as oral as well as topical formulations to treat infections of these bacteria. The calculated TI values for all other extracts are shown in Table 4.

\subsection{Non-targeted GC-MS headspace analysis}

Volatile terpenoids are major contributors to antibacterial activity of many plant extracts (Guimaräes et al., 2019). Therefore, we chose to examine the volatile terpenoid contents of the extracts prepared from triphala and its component plants. GC-MS headspace analysis was selected to identify components in these extracts. Although we were most interested in identifying terpenoid components, our analysis was unbiased towards that phytochemical class and instead sought to identify all volatile compounds in the extracts. (Table 5) Optimised GC-MS parameters were previously developed in our group (Shalom \& Cock, 2018) and those parameters were employed in this study. Several peaks identified as monoterpenoids were evident in multiple of the extracts prepared from triphala and its component species. A peak at 13.92 min was particularly prevalent, being detected in all of the extracts analysed. Comparison of the mass spectra of this peak with the ChemSpider database identified this compound as methoxycitronellal. Similarly, a peak was present in all chromatograms at $16.75 \mathrm{~min}$. This compound was putatively identified as carvone. A further peak was detected at approximately $13.6 \mathrm{~min}$ in the triphala and T. bellirica methanolic and aqueous extracts, the T. chebula methanolic extract and the E. officianalis extracts. Analysis of the mass spectra of this peak identified this compound as camphor. A peak at $14.23 \mathrm{~min}$ in multiple extracts was identified as endo borneol. A further peak at 11.99 min was noted in the triphala, T. bellirica and T. chebula methanolic extracts, as well as the T. bellirica aqueous extract chromatograms. This compound was putatively identified as fenchone. The peaks present at 15.73 and 16.33 min in multiple extracts were identified as hyscylene and p-cumic aldehyde respectively. A peak was also detected at $14.56 \mathrm{~min}$ in all methanolic and aqueous extracts except the aqueous triphala extract. In contrast, this peak was lacking in all ethyl acetate extracts. Comparisons of the mass spectra of this peak with the ChemSpider data base putatively identified this compound as terpinen-4-ol. 
Several other monoterpenoids were also identified, although most of these were present in fewer of the analysed extracts. The peak at $14.95 \mathrm{~min}$ in the T. chebula methanolic extract was identified as terpineol by comparing its mass spectra with the ChemSpider database. A peak at 12.23 min was only present in the T. bellirica methanolic and aqueous chromatograms as well as in the $T$. chebula aqueous extract. This compound was putatively identified as linalool. Pinocarveol was only identified as the compound at $13.41 \mathrm{~min}$ in the aqueous triphala extract chromatogram. The sesquiterpenoid patchoulane was also identified in all methanolic extracts analysed by comparison of its mass spectra with the ChemSpider database.

\section{Discussion}

The extracts were tested at the concentration in which they were prepared as an approximation of how they have been used traditionally. This provided an initial, semiquantitative measure of antibacterial activity on a solid surface (agar), followed by a more sensitive determination of MIC in the broth microdilution assays. Although triphala is often used, and is a proportionate mixture of T. bellirica, T. chebula and E. officianalis, the separate components themselves have been shown to possess antimicrobial activity (Srikumar et al., 2007; Amanullah et al., 2010; Maji et al., 2010; Mehrotra et al., 2010; Hutchings and Cock, 2018; Mandeville and Cock, 2018). We set out to determine why triphala is commonly used as a formula and to investigate the activities and spectrum of activities against a panel of gastrointestinal bacteria that trigger a disease (diarrhoea) that may be traditionally treated by ingestion of concoctions of these plants.

The methanolic extracts are generally the most efficacious, with the best activities typically arising from the $T$. chebula component. Perhaps more interestingly are the effects on bacteria when specific combinations of active extracts are used. Potentiation of the activity of one extract with another extract occurred in several cases, providing a basis for the medicinal benefits of the triphala formulation. These interactions are complex, since they appear to be influenced not only by the solvent that is used to prepare the extract, but also the individual plant components that are combined and the bacterial species that are affected. Isobologram plots also revealed insights into the nature of the interactions. In some cases, one of the two components tested acts as the potentiator, while in others it eliminates synergy, possibly acting in an irreversible or non-competitive manner. In yet another case, a very small proportion of one component is all that is necessary to produce synergistic inhibition of growth. Together, these findings suggest that individually tailored plant formulations may be designed to treat specific illnesses, based on the combinations of extract types used and the bacterial species 
involved in the disease. Additionally, it validates the use of the triphala components in mixtures, as they have been used traditionally for centuries, by providing a basis for implementing specific combinations of the plant extracts to boost activities against microbial triggers of disease.

Future investigations will be geared towards determining an expanded spectrum of activity against other bacterial pathogens, and to provide additional targeted therapies by altering the ratios of the components used. This may be further enhanced by studying the effects of a three-component system that involves T. bellirica, T. chebula and E. officianalis in specific ratios on bacterial growth, and to determine the mechanisms behind their bacteriostatic or bactericidal properties, with particular emphasis on the potentiation of these activities when extracts are used in mixtures.

Qualitative GC-MS analysis of the triphala, T. bellirica, T. chebula and E. officianalis methanolic, aqueous and ethyl acetate extracts identified a number of interesting compounds which may contribute to the antibacterial and antibiotic growth inhibitory activities reported in our study. Notably, multiple monoterpenoids were putatively identified in in the extracts. Methoxycitronellal, endo-borneol, terpinen-4-ol and cumic aldehyde were particularly prevalent, being detected in at least one extracts prepared from triphala and from each of the component plants. Similarly, eucalyptol and fenchone were present in triphala, T. bellirica and T. chebula, but not in E. officianalis. Many of these terpenoids have potent broad-spectrum antibacterial activity (Rajput et al., 2017) and therefore may contribute to the bacterial growth inhibitory activity reported here. The sesquiterpenoid compound patchoulane was also detected in triphala, as well as in all component plants and may also contribute to the growth inhibitory activity, or to the potentiating activity of the triphala formulation. It is likely that other phytochemical classes also contribute to the growth inhibitory properties these extracts. The qualitative phytochemical analysis studies reported that polyphenolics, flavonoids and tannins were present in relative abundance in triphala and all of the component plants. As our study used GC-MS techniques to putatively identify the phytochemical composition of the extracts, it is likely that many of the mid to higher polarity compounds may have not been identified in this study. High levels and a diversity of tannins are a common feature of all Terminalia spp., included those examined in this study (Cock, 2015). For example, gallic acid, ellagic acid and their methylated derivatives, chebulic acid, galloyl pyrogallol, corilagen, punicalin, castalagin and chebulagic acid have previously been reported in similar T. chebula extracts to those tested in our study (Cock et al., 2019). These tannins have potent, broad spectrum growth inhibitory 
activity against a variety of bacterial species and function via multiple mechanisms, including interactions with cell surface proteins and intracellular enzymes (Hogg and Embery, 1982; WuYuan et al., 1988; Buzzini et al., 2008). Therefore, it is likely that the tannin components may also contribute to the bacterial growth inhibitory activity noted herein. Future studies will further examine the antibacterial and antibiotic potentiating activity of these compounds.

\section{Conclusions}

Our study shows that combining the plant components of triphala does indeed have substantial potentiating effects, greatly increasing the antibacterial activity of the mixture against some bacteria. As triphala and the individual components each inhibited the growth of all bacterial pathogens tested, we were unable to determine whether the combination also extends the antibacterial spectrum. However, our study tested against a limited panel of bacteria ( 8 species) and future studies testing against further bacterial species may also provide evidence of further benefits of using triphala compared to the use of the individual components.

\section{Conflicts of interest}

The authors declare that they have no conflicts of interest.

\section{Author contributions}

Mr Gagan Tiwana, Dr Matthew Cheesman and Dr Ian Cock performed the antimicrobial, phytochemical and toxicity studies. Mr Alan White performed the GC-MS analysis. Dr Matthew Cheesman and Dr Ian Cock conceived and supervised the study and all authors were involved in the preparation of the manuscript.

\section{Acknowledgements}

Financial support for this work was provided by the Environmental Futures Research Institute and the Quality Use of Medicines (QUM) Network, Griffith University, Australia.

\section{Abbreviations}

DMSO Dimethyl sulfoxide

EO Emblica officinalis

FIC Fractional inhibitory concentration

GC-MS Gas chromatography-mass spectrometry

$\mathrm{kHz} \quad$ Kilohertz

$\mathrm{LC}_{50} \quad 50 \%$ lethal concentration

MIC Minimum inhibitory concentration 
SEM Standard error of the mean

TA Triphala

TB Terminalia bellirica

TC Terminalia chebula

TI Therapeutic index

TIC Total ion count

ZOI Zone of inhibition

\section{References}

Amanullah S.A., Chandramoorthy H.C., Kumar V.A., Khatheeja S., 2011. Antimicrobial activity of Triphala against bacterial isolates from HIV infected patients. Jundishapur J. Microbiol. 4(Supplement 1), S9-S17.

Baliga, M.S., Meera, S., Mathai, B., Rai, M.P., Pawar, V., Palatty, P.L., 2012. Scientific validation of the ethnomedicinal properties of the Ayurvedic drug Triphala: A review. Chin. J. Integr. Med. 18(12), 946-954. https://doi.org/10.1007/s11655-012-1299-x

Bhunia, A.K., 2018. Bacillus cereus and Bacillus anthracis, in: Bhunia, A.K. (Ed.) Foodborne Microbial Pathogens: Mechanisms and Pathogenesis. Springer New York, New York, NY, pp. 193-207. https://doi.org/10.10007/978-1-4939-7349-1

Biradar, Y.S., Singh, R., Sharma, K., Dhalwal, K., Bodhankar, S.L., Khandelwal, K.R., 2008. Evaluation of anti-diarrhoeal property and acute toxicity of Triphala Mashi, an Ayurvedic $\begin{array}{llll}\text { formulation. } & \text { J. Herb. }\end{array}$ https://doi.org/10.1080/15228940802152869

Buzzini, P., Arapitsas, P., Goretti, M, Branda, E., Turchetti, B., Pinelli, P., Ieri, F., Romani, A., 2008. Antimicrobial and antiviral activity of hydrolysable tannins. Mini-Rev. Med. Chem. 8(12), 1179-1187. https://doi.org/10.2174/138955708786140990

Cabrera-Sosa, L., Ochoa, T.J., 2020. Escherichia coli Diarrhea, in: Ryan, E.T., Hill, D.R., Solomon, T., Aronson, N.E., Endy, T.P. (Eds.), Hunter's Tropical Medicine and Emerging Infectious Diseases (Tenth Edition). London, pp. 481-485. https://doi.org/10.1016/C2016-0-01879-X

Clinical and Laboratory Standards Institute. Performance standards for antimicrobial susceptibility testing, 29th ed. CLSI document M100. Clinical and Laboratory Standards Institute, Wayne, PA., 2019. 
Cock, I.E., Wright, M. H., Matthews, B., White, A. R., 2019. Bioactive compounds sourced from Terminalia spp. in bacterial malodour prevention: An effective alternative to chemical additives. Int. J. Cosmet. Sci. 41(5), 496-508. https://doi.org/10.1111/ics. 12567

Cock IE. Antimicrobial activity of Aloe barbadensis Miller leaf gel components. Int. J. Microbiol. 2008;4(2):1. https://doi.org/10.5580/15bc

Cock I.E., 2015. The medicinal properties and phytochemistry of plants of the genus Terminalia (Combretaceae). Inflammopharmacology 23(5), 203-229. https://doi.org/10.1007/s10787-015-0246-z

de Rapper, S., Kamatou, G., Viljoen, A., van Vuuren, S., 2013. The in vitro antimicrobial activity of Lavandula angustifolia essential oil in combination with other aromatherapeutic oils. Evid.-Based Complementary Altern. Med., 1-10. https://doi.org/10.1155/2013/852049

Doern, C.D, 2014. When does 2 plus 2 equal 5? A review of antimicrobial synergy testing. J. Clin. Microbiol. 52(12), 4124-4128. https://doi.org/0.1128/JCM.01121-14

Guimarães, A.C., Meireles, L.M., Lemos, M.F., Guimarães, M.C., Endringer, D.C., Fronza, M., Scherer, R., 2019. Antibacterial activity of terpenes and terpenoids present in essential oils. Molecules 24(13), 2471. https://doi.org/10.3390/molecules24132471

Hogg, S.D., Embery, G., 1982. Blood-group-reactive glycoprotein from human saliva interacts with lipoteichoic acid on the surface of Streptococcus sanguis cells. Arch. Oral Biol. 27(3), 261-268. https://doi.org/10.1016/0003-9969(82)90060-7

Hübsch, Z., Van Zyl, R.L., Cock, I.E., Van Vuuren, S.F., 2014. Interactive antimicrobial and toxicity profiles of conventional antimicrobials with Southern African medicinal plants. S. Afr. J. Bot. 93, 185-197. https://doi.org/10.1016/j.sajb.2014.04.005

Hutchings, A., Cock, I.E., 2018. An integrative antimicrobial activity of Embelicia officinalis Gaertn. fruit extracts and conventional antibiotics against some bacterial triggers of autoimmune inflammatory diseases. Pharmacogn. J. 10(4), 654-662. https://doi.org/10.5530/pj.2018.4.108

Ilanko, I., Cock, I.E., 2019. The interactive antimicrobial activity of conventional antibiotics and Petalostigma spp. extracts against bacterial triggers of some autoimmune inflammatory diseases. Pharmacogn. J. 11(2), 292-309. https://doi.org/10.5530/pj.2019.11.45 
Kotloff, K.L., Riddle, M.S., Platts-Mills, J.A., Pavlinac, P., Zaidi, A.K.M., 2018. Shigellosis. The Lancet. 391(10122), 801-812. https://doi.org/10.1016/S0140-6736(17)33296-8

Liu, J., Xie, L., Zhao, D., Yang, T., Hu, Y., Sun, Z., Yu, X., 2019. A fatal diarrhoea outbreak in farm-raised Deinagkistrodon acutus in China is newly linked to potentially zoonotic Aeromonas hydrophila. Transbound. Emerg. Dis. 66(1), 287-298. https://doi.org/10.1111/tbed.13020

Mabona, U., Viljoen, A., Shikanga, E., Marston, A., Van Vuuren, S., 2013. Antimicrobial activity of southern African medicinal plants with dermatological relevance: From an ethnopharmacological screening approach, to combination studies and the isolation of a $\begin{array}{llll}\text { bioactive compound. J. } & \text { Ethnopharmacol. }\end{array}$ https://doi.org/10.1016/j.jep.2013.03.056

Mahajan, D., Jain, S., 2015. Antimicrobial analysis of Triphala and comparison with its individual constituents. Ind. J. Pharm. Biol. Res. 3(3), 55. https://doi.org/10.30750/ijpbr.3.3.9

Maji S., Dandapat P., Ojha D., Maity C., Halder S.K., Das P.K., Mohapatra T., Pathak K., Pati B.R., Samanta A., Mondal K.C, 2010. In vitro antimicrobial potentialities of different Solvent extracts of ethnomedicinal plants against clinically isolated human pathogens. J. Phytol. 2(4), 57-64.

Mandeville, A., Cock, I.E., 2018. Terminalia chebula Retz. extracts inhibit bacterial triggers of some autoimmune diseases and potentiate the activity of tetracycline. Indian J. Microbiol. 58(4), 496-506. https://doi.org/10.1007/s12088-018-0754-9

Mehrotra S., Srivastava A.K., Nandi S.P., 2010. Comparative antimicrobial activities of Neem, Amla, Aloe, Assam Tea and Clove extracts against Vibrio cholerae, Staphylococcus aureus and Pseudomonas aeruginosa. J. Med. Plants Res. 4(18), 2473-8.

Mukherjee, P.K., Rai, S., Bhattacharyya, S., Kumar Debnath, P., Biswas, T.K., Jana, U., Pandit, S., Saha, B.P., Paul, P.K., 2006. Clinical study of Triphala - a well known phytomedicine from India. Iranian J. Pharmacol. Ther. 5, 51-54.

Mukherjee, P.K., Harwansh, R.K., Bahadur, S., Banerjee, S., Kar, A., Chanda, J., Biswas, S., Ahmmed, S.M., Katiyar, C.K., 2017. Development of Ayurveda - Tradition to trend. J. Ethnopharmacol. 197, 10-24. https://doi.org/10.1016/j.jep.2016.09.024 
Murray, B.E., 1990. The life and times of the Enterococcus. Clin. Microbiol. Rev. 3(1), 46-65. https://doi.org/10.1128/cmr.3.1.46-65.1990

Orchard, A., Viljoen, A., van Vuuren, S., 2018a. Antimicrobial essential oil combinations to combat foot odour. Planta Med. 84(09/10), 662-673. https://doi.org/10.1055/a-05928022

Orchard, A., Viljoen, A., van Vuuren, S., 2018b. Wound pathogens: Investigating antimicrobial activity of commercial essential oil combinations against reference strains. Chem. Biodivers. 15(12), e1800405. https://doi.org/10.1002/cbdv.201800405

Orchard, A., van Vuuren, S.F., Viljoen, A.M., 2019. Commercial essential oil combinations against topical fungal pathogens. Nat. Prod. Commun. 14(1), 151-158. https://doi.org/10.1177/1934578x1901400139

Parveen, R., Shamsi, T.N., Singh, G., Athar, T., Fatima, S., 2018. Phytochemical analysis and In-vitro Biochemical Characterization of aqueous and methanolic extract of Triphala, a conventional herbal remedy. Biotechnol. Rep. 17, 126-136. https://doi.org/10.1016/j.btre.2018.02.003

Polage, C.R., Solnick, J.V., Cohen, S.H., 2012. Nosocomial diarrhea: Evaluation and treatment of causes other than Clostridium difficile. Clin. Infect. Dis. 55(7), 982-989. https://doi.org/10.1093/cid/cis551

Rajput, J. D., Bagul, S. D., Pete, U. D., Zade, C. M., Padhye, S. B., Bendre, R. S., 2017. Perspectives on medicinal properties of natural phenolic monoterpenoids and their hybrids. Mol. Divers. 22, 225-245. https://doi.org/10.1007/s11030-017-9787-y

Ruebhart, D. R., Wickramasinghe, W., \& Cock, I. E., 2009. Protective efficacy of the antioxidants Vitamin E and Trolox against Microcystis aeruginosa and microcystin-LR in Artemia franciscana nauplii. J. Toxicol. Environ. Health A. 72(24), 1567-1575. https://doi.org/10.1080/15287390903232459

Shalom, J., Cock, I.E., 2018. Terminalia ferdinandiana Exell. fruit and leaf extracts inhibit proliferation and induce apoptosis in selected human cancer cell lines. Nutr. Cancer. 70(4), 579-593. https://doi.org/10.1080/01635581.2018.1460680

Sheta M.M., Kikani K.M., Kavithia P., Thakkar J., Rangnani T., 2016. Study of antimicrobial activity of Triphala and its individual components. Int. J. Herb. Med. 4, 41-3. 
Sibandze, G.F., van Zyl, R.L., van Vuuren, S.F., 2010. The anti-diarrhoeal properties of Breonadia salicina, Syzygium cordatum and Ozoroa sphaerocarpa when used in combination in Swazi traditional medicine. J. Ethnopharmacol. 132(2), 506-511. https://doi.org/10.1016/j.jep.2010.08.050

Srikumar, R., Parthasarathy, N.J., Shankar, E.M., Manikandan, S., Vijayakumar, R., Thangaraj, R., Vijayananth, K., Sheeladevi, R., Rao, U.A., 2007. Evaluation of the growth inhibitory activities of Triphala against common bacterial isolates from HIV infected patients. Phytother. Res. 21(5), 476-480. https://doi.org/10.1002/ptr.2105

Tambekar D.H., Khante B.S., Dahikar S.B., Banginwar Y.S., 2007. Antibacterial properties of contents of Triphala: A traditional Indian herbal preparation. Continental J. Microbiol. 1, $8-12$.

Tambekar D.H., Dahikar S.B., 2011. Antibacterial activity of some Indian Ayurvedic preparations against enteric bacterial pathogens. J. Adv. Pharm. Technol. Res. 2(1), 2429. https://doi.org/10.4103/2231-4040.79801

van Vuuren, S., Viljoen, A., 2011. Plant-based antimicrobial studies - methods and approaches to study the interaction between natural products. Planta Med. 77(11), 1168-1182. https://doi.org/10.1055/s-0030-1250736

Vesoul, J., Cock, I., 2011. An examination of the medicinal potential of Pittosporum phylliraeoides: toxicity, antibacterial and antifungal activities. Pharmacogn. Commun. 1(2), 8-17. https://doi.org/10.5530/pc.2011.2.3

Wotzka, S.Y., Nguyen, B.D., Hardt, W.-D., 2017. Salmonella Typhimurium diarrhea reveals basic principles of enteropathogen infection and disease-promoted DNA exchange. Cell Host Microbe. 21(4), 443-454. https://doi.org/10.1016/j.chom.2017.03.009

Wu-Yuan, C.D., Chen, C.Y., Wu, R.T., 1988. Gallotannins inhibit growth, water soluble glucan synthesis, and aggregation of mutans streptococci. J. Dental Res. 67, 51-55. https://doi.org/10.1177/00220345880670011001 
Fig. 1. Antibacterial activities of extracts and reference antibiotics against $E$. coli (A), S. sonnei (B), A. hydrophila (C), S. Typhimurium (D), S. flexneri (E), S. aureus (F), B. cereus (G) and E. faecalis $(\mathrm{H})$ by disc diffusion assays measured as ZOI in $\mathrm{mm}$. The negative control discs $(\mathrm{N})$ contained 1\% DMSO. Values are expressed as mean \pm SEM of triplicate assays. Results are shown as significantly different to the negative control if $p<0.05(*)$ or $p<0.01$ (**), and highly statistically significant if $p<0.001(* * *)$. TA $=$ triphala, $\mathrm{TB}=T$. bellirica; $\mathrm{TC}=T$. chebula $; \mathrm{EO}=$ E. officinalis $;$ Pen = penicillin, Ery = erythromycin, Tet $=$ tetracycline, $\mathrm{Chl}=$ chloramphenicol and Cip = ciprofloxacin. 
Fig. 2. Isobolograms for combinations of plant component extracts at various ratios that showed synergistic antibacterial activity as shown in Table 4 . $\mathrm{TA}=$ triphala, $\mathrm{TB}=T$. bellirica $\mathrm{TC}=$ T. chebula $\mathrm{EO}=$ E. officinalis. The graphs are: $\mathrm{TB}+\mathrm{TC}(\mathrm{A})$ and $\mathrm{TB}+\mathrm{EO}$ (B) methanol extract combinations against E. coli; TB + TC (C), TB + EO (D) and TC + EO (E) methanol extracts against $A$. hydrophila, and TB + TC (F) aqueous extract combinations against $S$. flexneri. Results were generated from mean MIC values of four replicates for each extract. Ratio $=\%$ extract: $\%$ antibiotic. Ratios lying on or underneath the 0.5:0.5 line are considered to be synergistic $(\Sigma$ FIC $\leq 0.5)$. Any points between the 0.5:0.5 and 1.0:1.0 lines are deemed additive $(\Sigma$ FIC $>0.5-1.0)$. 


\section{Table 1}

Mass of dried extracted material, concentration after resuspension in $1 \%$ DMSO, and qualitative phytochemical screenings of the resuspended extracts. $\mathrm{TA}=$ triphala, $\mathrm{TB}=$ Terminalia bellirica $; \mathrm{TC}=$ Terminalia chebula $; \mathrm{EO}=$ Emblica officinalis. +++ indicates a large response; ++ indicates a moderate response; + indicates a minor response; - indicates no response in the assay.

\begin{tabular}{|c|c|c|c|c|c|c|c|c|c|c|c|c|c|}
\hline 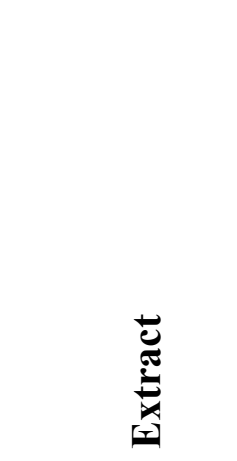 & 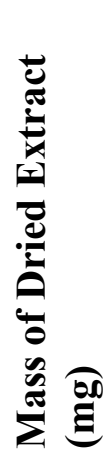 & 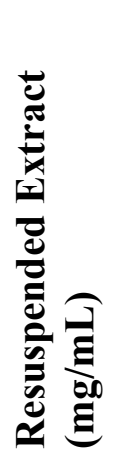 & 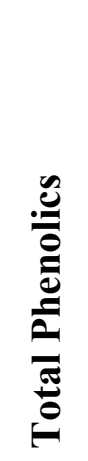 & 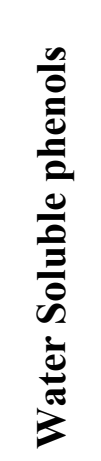 & 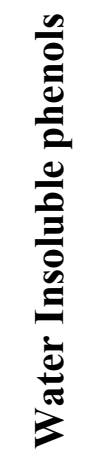 & 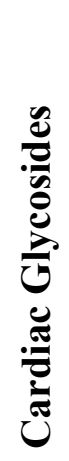 & 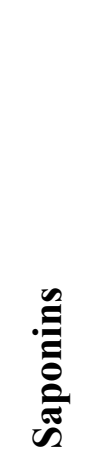 & 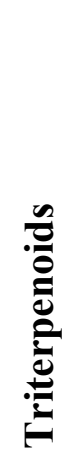 & $\frac{n}{0}$ & $\frac{\substack{0 \\
\frac{0}{0}}}{\frac{\pi}{\pi}}$ & $\begin{array}{l}\frac{n}{0} \\
\frac{\pi}{0} \\
\frac{\pi}{\pi}\end{array}$ & 氖 & : \\
\hline $\begin{array}{l}\text { Aqueous } \\
\text { TA } \\
\text { TB } \\
\text { TC } \\
\text { EO }\end{array}$ & $\begin{array}{l}686 \\
474 \\
567 \\
361 \\
\end{array}$ & $\begin{array}{l}68.6 \\
47.4 \\
56.7 \\
36.1\end{array}$ & $\begin{array}{l}+++ \\
+++ \\
+++ \\
+++\end{array}$ & $\begin{array}{l}+++ \\
+++ \\
+++ \\
+++\end{array}$ & $\begin{array}{l}+++ \\
+++ \\
+++ \\
+++\end{array}$ & $\begin{array}{l}- \\
- \\
- \\
-\end{array}$ & $\begin{array}{l}- \\
- \\
+ \\
-\end{array}$ & $\begin{array}{l}- \\
- \\
- \\
-\end{array}$ & $\begin{array}{l}- \\
- \\
- \\
-\end{array}$ & $\begin{array}{l}- \\
- \\
- \\
+\end{array}$ & $\begin{array}{l}+++ \\
+++ \\
+++ \\
+++\end{array}$ & $\begin{array}{l}+++ \\
+++ \\
+++ \\
+++\end{array}$ & $\begin{array}{l}- \\
- \\
- \\
-\end{array}$ \\
\hline $\begin{array}{l}\text { Methanolic } \\
\text { TA } \\
\text { TB } \\
\text { TC } \\
\text { EO }\end{array}$ & $\begin{array}{l}404 \\
368 \\
707 \\
544\end{array}$ & $\begin{array}{l}40.4 \\
36.8 \\
70.7 \\
54.4\end{array}$ & $\begin{array}{l}+++ \\
+++ \\
+++ \\
+++\end{array}$ & $\begin{array}{l}+++ \\
+++ \\
+++ \\
+++\end{array}$ & $\begin{array}{l}+++ \\
+++ \\
+++ \\
+++\end{array}$ & $\begin{array}{l}+ \\
+ \\
+ \\
+\end{array}$ & $\begin{array}{c}- \\
- \\
+++ \\
-\end{array}$ & $\begin{array}{l}++ \\
++ \\
++ \\
++\end{array}$ & $\begin{array}{l}- \\
- \\
-\end{array}$ & $\begin{array}{l}- \\
- \\
+ \\
-\end{array}$ & $\begin{array}{l}+++ \\
+++ \\
+++ \\
+++\end{array}$ & $\begin{array}{l}+++ \\
+++ \\
+++ \\
+++\end{array}$ & $\begin{array}{l}- \\
- \\
- \\
-\end{array}$ \\
\hline $\begin{array}{l}\text { Ethyl acetate } \\
\text { TA } \\
\text { TB } \\
\text { TC } \\
\text { EO }\end{array}$ & $\begin{array}{l}19 \\
52 \\
44 \\
34\end{array}$ & $\begin{array}{l}1.9 \\
5.2 \\
4.4 \\
3.4\end{array}$ & $\begin{array}{l}+++ \\
+++ \\
+++ \\
+++\end{array}$ & $\begin{array}{l}+++ \\
+++ \\
+++ \\
+++\end{array}$ & $\begin{array}{l}+++ \\
+++ \\
+++ \\
+++\end{array}$ & $\begin{array}{l}- \\
- \\
- \\
-\end{array}$ & $\begin{array}{l}- \\
- \\
- \\
-\end{array}$ & $\begin{array}{l}- \\
- \\
- \\
-\end{array}$ & $\begin{array}{l}- \\
- \\
- \\
-\end{array}$ & $\begin{array}{l}- \\
- \\
-\end{array}$ & $\begin{array}{c}++ \\
++ \\
+++ \\
+\end{array}$ & $\begin{array}{l}+++ \\
+++ \\
+++ \\
+++\end{array}$ & $\begin{array}{l}- \\
- \\
- \\
-\end{array}$ \\
\hline
\end{tabular}




\section{Table 2}

MIC values $(\mu \mathrm{g} / \mathrm{mL})$ for the aqueous, methanolic and ethyl acetate triphala, $T$. bellirica, $T$. chebula and E. officinalis extracts and the reference (positive control) antibiotics against the eight bacterial strains tested in this study.

\begin{tabular}{|c|c|c|c|c|c|c|c|c|c|}
\hline \multirow[b]{2}{*}{ 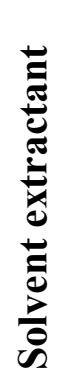 } & \multirow[b]{2}{*}{ 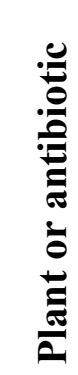 } & \multicolumn{8}{|c|}{$\operatorname{MIC}(\mu \mathrm{g} / \mathrm{mL})$} \\
\hline & & $\begin{array}{l}\ddot{8} \\
\ddot{8}\end{array}$ & $\underbrace{\frac{\tilde{J}}{\tilde{J}}}_{10 i}$ & 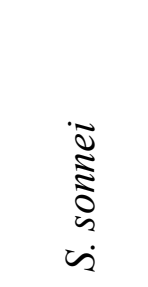 & 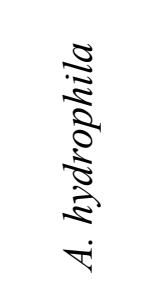 & 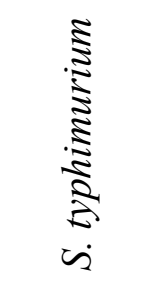 & $\underset{\dot{s}}{\stackrel{5}{\vdots}}$ & 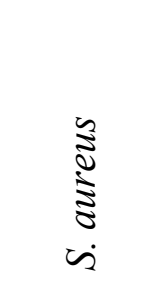 & 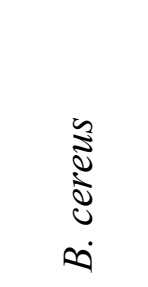 \\
\hline \multirow{4}{*}{ 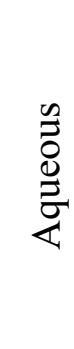 } & TA & 8575 & 8575 & 4287 & 4287 & 4287 & 4287 & 8575 & 8575 \\
\hline & TB & 5925 & 5925 & 2962 & 370 & 2962 & 1481 & 741 & 5925 \\
\hline & TC & 7087 & 7087 & 3544 & 3544 & 3544 & 1772 & 3544 & 1772 \\
\hline & EO & 9025 & 4512 & 2256 & 2256 & 2256 & 2256 & 4512 & 2256 \\
\hline \multirow{4}{*}{ 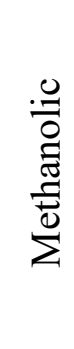 } & TA & 2525 & 2525 & 2525 & 631 & 2525 & 631 & 1262 & 1262 \\
\hline & TB & 1150 & 2300 & 1150 & 575 & 1150 & 287 & 575 & 575 \\
\hline & TC & 2209 & 2209 & 2209 & 1105 & 2209 & 276 & 552 & 1105 \\
\hline & EO & 3400 & 3400 & 3400 & 3400 & 3400 & 1700 & 1700 & 1700 \\
\hline \multirow{4}{*}{ 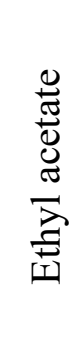 } & TA & $>10000$ & $>10000$ & $>10000$ & 475 & $>10000$ & 475 & $>10000$ & $>10000$ \\
\hline & TB & $>10000$ & $>10000$ & $>10000$ & 325 & $>10000$ & 325 & 1300 & 1300 \\
\hline & TC & $>10000$ & $>10000$ & $>10000$ & 550 & 1100 & 550 & 1100 & 550 \\
\hline & EO & $>10000$ & $>10000$ & $>10000$ & $>10000$ & $>10000$ & $>10000$ & $>10000$ & $>10000$ \\
\hline \multirow{5}{*}{ 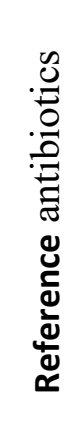 } & Pen & $>2.5$ & $>2.5$ & $>2.5$ & $>2.5$ & 2.5 & $>2.5$ & $>2.5$ & $>2.5$ \\
\hline & Ery & 0.625 & $>2.5$ & $>2.5$ & $>2.5$ & $>2.5$ & $>2.5$ & 0.625 & 0.078 \\
\hline & Tet & 0.625 & 0.625 & 0.313 & 0.313 & 0.625 & 0.625 & 0.313 & 0.313 \\
\hline & Chl & $>2.5$ & 1.25 & 1.25 & 0.625 & 1.25 & 0.625 & $>2.5$ & $>2.5$ \\
\hline & Cip & 0.625 & $<0.02$ & $<0.02$ & $<0.02$ & $<0.02$ & $<0.02$ & 0.156 & 0.156 \\
\hline
\end{tabular}

$\mathrm{TA}=$ triphala, $\mathrm{TB}=T$. bellirica, $\mathrm{TC}=T$. chebula, $\mathrm{EO}=$ E. officinalis. MIC values for extracts with noteworthy activity $(400-1000 \mu \mathrm{g} / \mathrm{ml})$ are in bold while those with good activity (100- 
$400 \mu \mathrm{g} / \mathrm{ml}$ ) are italicised . Pen = penicillin; Ery = erythromycin; Tet = tetracycline; Chl = chloramphenicol; Cip = ciprofloxacin. The range of concentrations used in the assays was 0.01 $-15 \mathrm{mg} / \mathrm{ml}$ for the plant extracts and $0.01-2.5 \mu \mathrm{g} / \mathrm{ml}$ for the reference antibiotics. 


\section{Table 3}

FIC and $\sum$ FIC values, where relevant, for the combinations of the methanolic T. bellirica, $T$. chebula and E. officinalis extracts against seven of the bacterial strains used in this study.

\begin{tabular}{|c|c|c|c|c|c|c|c|c|c|}
\hline \multirow[b]{2}{*}{ 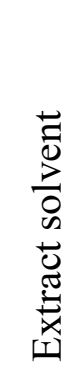 } & \multirow[b]{2}{*}{ 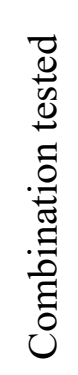 } & \multirow[b]{2}{*}{ 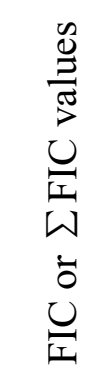 } & \multicolumn{7}{|c|}{ Bacterial strain } \\
\hline & & & $\begin{array}{l}\stackrel{\overrightarrow{0}}{8} \\
\dot{0}\end{array}$ & 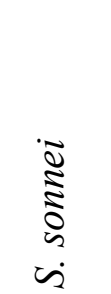 & 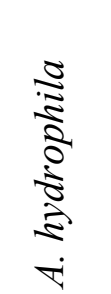 & 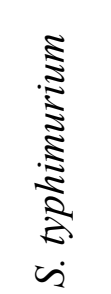 & 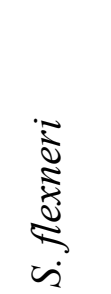 & 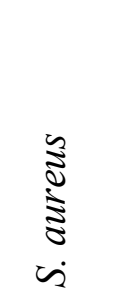 & 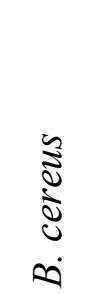 \\
\hline \multirow{9}{*}{ 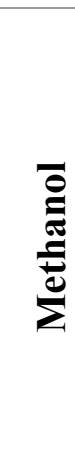 } & \multirow{3}{*}{$\begin{array}{c}\text { TB } \\
+ \\
\text { TC }\end{array}$} & $\mathrm{FIC}_{\mathrm{TB}}$ & 0.225 & 0.134 & 0.224 & 0.500 & 0.500 & 0.500 & 0.500 \\
\hline & & $\mathrm{FIC}_{\mathrm{TC}}$ & 0.219 & 0.468 & 0.219 & 0.500 & 1.000 & 1.000 & 0.499 \\
\hline & & $\sum$ FIC & 0.444 & 0.602 & 0.443 & 1.000 & 1.500 & 1.500 & 0.999 \\
\hline & \multirow{3}{*}{$\begin{array}{c}\text { TB } \\
+ \\
\text { EO }\end{array}$} & $\mathrm{FIC}_{\mathrm{TB}}$ & 0.225 & 0.500 & 0.318 & 1.000 & 1.000 & 0.500 & 0.500 \\
\hline & & FICEO & 0.103 & 0.250 & 0.125 & 0.523 & 0.250 & 0.250 & 0.250 \\
\hline & & $\sum$ FIC & 0.328 & 0.750 & 0.431 & 1.523 & 1.250 & 0.750 & 0.750 \\
\hline & \multirow{3}{*}{$\begin{array}{c}\text { TC } \\
+ \\
\text { EO }\end{array}$} & $\mathrm{FIC}_{\mathrm{TC}}$ & 0.421 & 0.500 & 0.219 & 0.500 & 2.000 & 1.000 & 0.499 \\
\hline & & $\mathrm{FIC}_{\mathrm{EO}}$ & 0.103 & 0.250 & 0.063 & 0.250 & 0.250 & 0.250 & 0.250 \\
\hline & & $\sum$ FIC & $\mathbf{0 . 5 2 3}$ & 0.750 & 0.281 & 0.750 & 2.250 & 1.250 & 0.749 \\
\hline
\end{tabular}

Synergistic $\sum$ FIC values $(\leqslant 0.5)$ are shown in italics, and additive values $(>0.5-\leqslant 1.0)$ in bold. Indifferent values are $>1.0-\leqslant 4.0$. Antagonistic interactions $(>4.0)$ were not observed. $\mathrm{TB}=T$. bellirica, $\mathrm{TC}=T$. chebula, $\mathrm{EO}=$ E. officinalis. 


\section{Table 4}

Therapeutic index values (TI) for extracts of triphala and each of the botanical components against the tested bacterial species.

\begin{tabular}{|c|c|c|c|c|c|c|c|c|c|}
\hline$\stackrel{\Xi}{\Xi}$ & 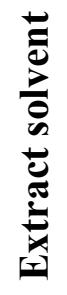 & $\underset{8}{\tilde{8}}$ & 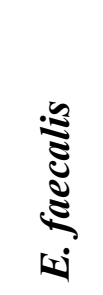 & 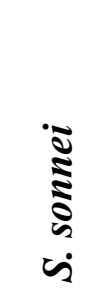 & 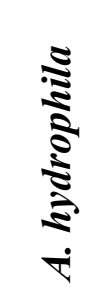 & 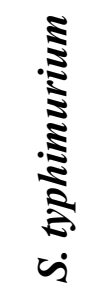 & & 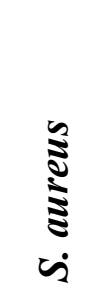 & 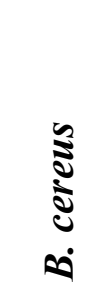 \\
\hline \multirow{3}{*}{ TA } & $\mathbf{M}$ & 0.3 & 0.3 & 0.3 & 1.19 & 0.3 & 1.19 & 0.59 & 0.59 \\
\hline & $\mathbf{W}$ & 0.09 & 0.09 & 0.18 & 0.18 & 0.18 & 0.18 & 0.09 & 0.09 \\
\hline & $\mathbf{E}$ & High & High & High & High & High & High & High & High \\
\hline \multirow{3}{*}{ TB } & M & High & High & High & High & High & High & High & High \\
\hline & $\mathbf{W}$ & 0.13 & 0.13 & 0.25 & 2.03 & 0.25 & 0.51 & 1.01 & 0.13 \\
\hline & $\mathbf{E}$ & High & High & High & High & High & High & High & High \\
\hline \multirow{3}{*}{$\mathbf{T C}$} & M & High & High & High & High & High & High & High & High \\
\hline & $\mathbf{W}$ & 0.11 & 0.11 & 0.21 & 0.21 & 0.21 & 0.42 & 0.21 & 0.42 \\
\hline & $\mathbf{E}$ & CND & CND & CND & 1.36 & 0.68 & 1.36 & 0.68 & 1.36 \\
\hline \multirow{3}{*}{ EO } & M & 0.22 & 0.22 & 0.22 & 0.22 & 0.22 & 0.44 & 0.44 & 0.44 \\
\hline & $\mathbf{W}$ & 0.08 & 0.17 & 0.33 & 0.33 & 0.33 & 0.33 & 0.17 & 0.33 \\
\hline & $\mathbf{E}$ & CND & CND & CND & CND & CND & CND & CND & CND \\
\hline
\end{tabular}

Numerical values were determined by $\mathrm{LC}_{50} / \mathrm{MIC}$. High $=\mathrm{TI}$ could not be determined as no toxicity was observed at the highest concentrations; these were therefore deemed to have high TI values. CND indicates that a TI could not be determined as the extract was inactive against the indicated bacterial species. $\mathrm{TA}=$ triphala, $\mathrm{TB}=T$. bellirica, $\mathrm{TC}=T$. chebula, $\mathrm{EO}=E$. officinalis. 


\section{Table 5}

Qualitative GC-MS headspace analysis of extracts prepared from triphala and its components, elucidation of empirical formulas, relative abundances and putative identification of each compound where possible. $\mathrm{TA}=$ triphala, $\mathrm{TB}=T$. bellirica, $\mathrm{TC}=T$. chebula, $\mathrm{EO}=$ E. officinalis .

\begin{tabular}{|c|c|c|c|c|c|c|c|c|c|c|c|c|c|c|c|}
\hline \multirow{3}{*}{$\begin{array}{c}\text { Retention } \\
\text { Time } \\
\text { (min) }\end{array}$} & \multirow{3}{*}{$\begin{array}{l}\text { MW } \\
\text { (Da) }\end{array}$} & \multirow{3}{*}{$\begin{array}{c}\text { Empirical } \\
\text { Formula }\end{array}$} & \multirow{3}{*}{$\begin{array}{c}\text { Putative } \\
\text { Identification }\end{array}$} & \multicolumn{3}{|c|}{ TA } & \multicolumn{3}{|c|}{ TB } & \multicolumn{3}{|c|}{ TC } & \multicolumn{3}{|c|}{ EO } \\
\hline & & & & \multicolumn{12}{|c|}{ Relative abundances (\% of peak area compared to total area under chromatogram) } \\
\hline & & & & M & $\mathbf{W}$ & $\mathbf{E}$ & $\mathbf{M}$ & $\mathbf{W}$ & $\mathbf{E}$ & $\mathbf{M}$ & $\mathbf{W}$ & $\mathbf{E}$ & $\mathbf{M}$ & $\mathbf{W}$ & $\mathbf{E}$ \\
\hline 4.29 & 100 & $\mathrm{C}_{10} \mathrm{H}_{12} \mathrm{O}$ & Hexanal & - & 1.37 & - & - & 0.74 & - & - & 0.61 & - & - & - & - \\
\hline 4.59 & 116 & $\mathrm{C}_{6} \mathrm{H}_{12} \mathrm{O}_{2}$ & n-Butyl acetate & - & - & 0.09 & - & - & - & - & - & 1.25 & - & - & - \\
\hline 4.78 & 78 & $\mathrm{C}_{2} \mathrm{H}_{6} \mathrm{OS}$ & DMSO & 68.11 & 85.34 & 97.56 & 19.47 & 88.15 & 98.52 & 58.25 & 94.93 & 90.36 & 49.04 & 95.78 & 92.83 \\
\hline 6.646 & 118 & $\mathrm{C}_{6} \mathrm{H}_{14} \mathrm{O}_{2}$ & 2-Butoxy-ethanol, & 27.29 & 0.49 & 0.07 & 19.81 & 0.41 & 0.08 & 33.05 & 0.17 & - & 44.44 & 0.21 & - \\
\hline 8.018 & 112 & $\mathrm{C}_{7} \mathrm{H}_{12} \mathrm{O}$ & (E)-2-Heptenal & - & 1.31 & - & - & 0.25 & - & 0.41 & - & - & - & 0.19 & - \\
\hline 8.647 & 158 & $\mathrm{C}_{10} \mathrm{H}_{22} \mathrm{O}$ & n-Propyl heptyl ether & 0.35 & 0.52 & 0.05 & 0.18 & 0.33 & - & 0.42 & 0.25 & 0.09 & - & 0.23 & - \\
\hline 9.346 & 130 & $\mathrm{C}_{8} \mathrm{H}_{18} \mathrm{O}$ & Octanal & 0.18 & 0.51 & 0.11 & 0.1 & 0.48 & 0.06 & 0.46 & 0.15 & 0.77 & 0.24 & 0.4 & 0.3 \\
\hline 10.122 & 130 & $\mathrm{C}_{8} \mathrm{H}_{18} \mathrm{O}$ & 2-Ethyl-1-hexanol & 1.17 & 0.19 & 0.45 & 0.32 & 0.02 & 0.08 & 1.5 & 0.05 & 3.64 & 1.66 & - & 1.26 \\
\hline 10.221 & 154 & $\mathrm{C}_{10} \mathrm{H}_{18} \mathrm{O}$ & Eucalyptol & - & 0.57 & - & 0.38 & 1.23 & - & 0.22 & - & - & - & - & - \\
\hline 10.963 & 126 & $\mathrm{C}_{8} \mathrm{H}_{14} \mathrm{O}$ & 2-Octenal & - & 0.31 & - & - & - & - & 0.13 & - & - & - & - & - \\
\hline 11.355 & 130 & $\mathrm{C}_{8} \mathrm{H}_{18} \mathrm{O}$ & 1-Octanol & 0.39 & 0.26 & - & 0.23 & 0.55 & - & 0.75 & - & 0.16 & 0.24 & - & - \\
\hline 11.667 & 125 & $\mathrm{C}_{8} \mathrm{H}_{15} \mathrm{~N}$ & Octanenitrile & - & - & - & 0.06 & - & - & - & - & - & - & - & - \\
\hline 11.986 & 152 & $\mathrm{C}_{10} \mathrm{H}_{16} \mathrm{O}$ & L-Fenchone & 0.18 & - & - & 0.44 & 1.71 & - & 0.35 & - & - & - & - & - \\
\hline 12.226 & 154 & $\mathrm{C}_{10} \mathrm{H}_{18} \mathrm{O}$ & Linalool & - & - & - & 0.05 & 0.36 & - & - & 0.05 & - & - & - & - \\
\hline 12.344 & 142 & $\mathrm{C}_{9} \mathrm{H}_{18} \mathrm{O}$ & Nonanal & 0.24 & 0.08 & - & 0.29 & 0.47 & 0.02 & 0.82 & 0.16 & 0.14 & 0.21 & 0.07 & - \\
\hline
\end{tabular}




\begin{tabular}{|c|c|c|c|c|c|c|c|c|c|c|c|c|c|c|c|}
\hline 12.72 & \multicolumn{3}{|c|}{ Unable to determine } & 0.03 & 0.06 & - & - & 0.05 & - & 0.08 & 0.08 & - & 0.05 & 0.05 & - \\
\hline 13.41 & 152 & $\mathrm{C}_{10} \mathrm{H}_{16} \mathrm{O}$ & Pinocarveol & - & 0.03 & - & - & - & - & - & - & - & - & - & - \\
\hline 13.597 & 152 & $\mathrm{C}_{10} \mathrm{H}_{16} \mathrm{O}$ & Camphor & 0.16 & 0.46 & - & 0.25 & 1.07 & - & 0.05 & - & - & - & 0.04 & - \\
\hline 13.917 & 186 & $\mathrm{C}_{11} \mathrm{H}_{22} \mathrm{O}_{2}$ & Methoxycitronellal & 0.34 & 3.16 & 0.17 & 0.22 & 0.45 & 0.15 & 0.36 & 0.62 & 0.21 & 0.35 & 0.37 & 0.43 \\
\hline 14.231 & 154 & $\mathrm{C}_{10} \mathrm{H}_{18} \mathrm{O}$ & Endo-borneol & - & 0.06 & - & 0.02 & 0.1 & - & 0.16 & - & - & 0.08 & 0.07 & - \\
\hline 14.559 & 154 & $\mathrm{C}_{19} \mathrm{H}_{18} \mathrm{O}$ & Terpinen-4-ol & 0.06 & - & - & 0.16 & 0.11 & - & 0.26 & 0.46 & - & 0.03 & 0.04 & - \\
\hline 14.952 & 154 & $\mathrm{C}_{19} \mathrm{H}_{18} \mathrm{O}$ & Terpineol & - & - & - & - & - & - & 0.03 & - & - & - & - & - \\
\hline 15.158 & 156 & $\mathrm{C}_{11} \mathrm{H}_{24}$ & 2-Methyl-decane & 0.11 & 0.19 & 0.05 & 0.05 & 0.16 & 0.02 & 0.19 & 0.07 & 0.05 & 0.06 & 0.07 & 0.12 \\
\hline 15.447 & \multicolumn{3}{|c|}{ Unable to determine } & 0.1 & 0.09 & 0.18 & 0.05 & 0.07 & 0.07 & 0.26 & - & 0.57 & 0.25 & 0.05 & 0.68 \\
\hline 15.549 & 138 & $\mathrm{C}_{9} \mathrm{H}_{14} \mathrm{O}$ & (E,E)-2,4-Nonadienal & - & 0.02 & - & - & - & 0.08 & 0.02 & - & 0.14 & - & - & 0.08 \\
\hline 15.726 & 166 & $\mathrm{C}_{10} \mathrm{H}_{14} \mathrm{O}_{2}$ & Hyscylene & 0.04 & - & 0.04 & - & 0.06 & - & 0.62 & 0.08 & 0.04 & - & - & 0.22 \\
\hline 16.334 & 148 & $\mathrm{C}_{10} \mathrm{H}_{12} \mathrm{O}$ & p-Cumic aldehyde & - & - & - & 0.11 & 0.19 & - & 0.08 & 0.13 & - & 0.04 & - & - \\
\hline 16.745 & 150 & $\mathrm{C}_{10} \mathrm{H}_{14} \mathrm{O}$ & Carvone & 0.29 & 0.11 & 0.13 & 0.17 & 0.34 & 0.12 & 0.28 & 0.34 & 0.18 & 0.03 & 0.31 & 0.42 \\
\hline 16.901 & 154 & $\mathrm{C}_{10} \mathrm{H}_{18} \mathrm{O}$ & (E)-2-Decenal & 0.04 & 0.11 & - & 0.02 & 0.05 & - & 0.2 & - & - & 0.32 & & - \\
\hline 17.029 & 158 & $\mathrm{C}_{9} \mathrm{H}_{18} \mathrm{O}_{2}$ & Nonanoic acid & 0.02 & - & - & 0.02 & - & - & 0.03 & - & - & - & - & - \\
\hline 17.228 & 148 & $\mathrm{C}_{10} \mathrm{H}_{12} \mathrm{O}$ & 2-Phenylbutanal & 0.11 & - & 0.11 & 0.05 & 0.07 & 0.04 & 0.13 & 0.03 & 0.32 & 0.21 & 0.04 & 1.55 \\
\hline 18.66 & & & & - & 0.03 & 0.03 & 0.04 & 0.04 & 0.03 & 0.03 & - & 0.14 & 0.09 & 0.1 & 0.12 \\
\hline 19.426 & 286 & $\mathrm{C}_{16} \mathrm{H}_{30} \mathrm{O}_{4}$ & $\begin{array}{l}\text { 2,2,4-Trimethyl-1,3- } \\
\text { pentanediol } \\
\text { diisobutyrate }\end{array}$ & - & 0.46 & 0.16 & 0.02 & 0.39 & 0.06 & - & 0.25 & 0.31 & 0.09 & 0.4 & 0.19 \\
\hline 19.984 & 216 & $\mathrm{C}_{12} \mathrm{H}_{24} \mathrm{O}_{3}$ & $\begin{array}{l}\text { 2-Ethyl-3- } \\
\text { hydroxyhexyl 2- } \\
\text { methylpropanoate }\end{array}$ & 0.04 & 0.79 & 0.26 & 0.04 & 0.66 & 0.11 & 0.03 & 0.45 & 0.51 & 0.1 & 0.71 & 0.29 \\
\hline 22.919 & 206 & $\mathrm{C}_{15} \mathrm{H}_{26}$ & Patchoulane & 0.08 & - & - & 0.04 & - & - & 0.07 & - & - & 0.39 & - & - \\
\hline 24.671 & \multirow{2}{*}{\multicolumn{3}{|c|}{ Unable to determine }} & 0.21 & 0.15 & 0.22 & 0.13 & 0.22 & 0.18 & 0.51 & 0.12 & 0.4 & 1.25 & 0.05 & 0.72 \\
\hline 27.504 & & & & 0.11 & 0.31 & 0.05 & - & - & 0.04 & 0.08 & - & 0.06 & 0.1 & 0.09 & 0.12 \\
\hline
\end{tabular}




\begin{tabular}{|c|c|c|c|c|c|c|c|c|c|c|c|c|c|c|c|}
\hline 27.599 & 286 & $\mathrm{C}_{16} \mathrm{H}_{18} \mathrm{O}_{3}$ & $\begin{array}{l}\text { 1-Isobutyl 4- } \\
\text { isopropyl 3- } \\
\text { isopropyl-2,2- } \\
\text { dimethylsuccinate }\end{array}$ & 0.15 & 0.38 & 0.15 & 0.26 & 0.11 & 0.11 & 0.16 & 0.19 & 0.18 & 0.42 & 0.45 & 0.39 \\
\hline
\end{tabular}

The relative abundance is a measure of the area under the peak expressed as a \% of the total area under all chromatographic peaks. - indicates that a compound was not detected in that extract. 